\title{
Research on Three-cup of Wind Speed Sensor
}

\author{
Weitao Zhang \\ School of North China Electric Power University, Baoding 071000, China
}

Keywords: Wireless and passive sensor, wind speed, wireless detection, spontaneous electricity

\begin{abstract}
Wireless and passive sensor has an important application in industry sector. This paper designs a spontaneous electricity wireless and passive air velocity sensor, which is based on the traditional three-cup of wind speed sensor. This paper also tests the characteristics of the sensor wirelessly. The result shows that the wireless and passive air velocity sensor which we designed has a perfect dynamic and static performance. Meanwhile, the new type sensor retains the advantages of traditional three-cup of wind speed sensor, which has a wide accommodation. Based on the above content, this paper proves the new sensor has great practical value.
\end{abstract}

\section{Introduction}

The active and wired sensors which need an external power to provide the energy is widely used in the monitoring system at present. There are a lot of problems in this way, which include the trouble in replacing the power supply, the huge volume and quality of measurement system and maintenance problems. By contrast, Wireless and passive sensor has incomparable advantages in the above areas. Wireless and passive sensor can especially satisfy some strict requirements in special environment, such as rotating member and sealing element. As a result, the development and application of wireless and passive sensor is growing rapidly in recent years. Some companies such as EnOcean in Germany developed the wireless energy harvesting technology to achieve the wireless passive measurements of the sensor. Nevertheless, the technology of the new sensor is complex and the cost is very high.

In this paper, according to "the monitoring variable of the sensor is its energy source "design philosophy, based on the traditional three-cup wind speed sensor, we implement wireless and passive wind speed sensor by spontaneous electricity. This design has the advantages of low cost and high maturity of the system. This paper studied the design of the device in detail, created and tested the performance of the device at the same time.

\section{The Measuring Principle of Three-cup Wind Speed Sensor}

In a stable air flow field, three-cup wind speed sensor begin to rotate under the ability of rotate. If the wind speed is constant, the resultant moment of wind speed sensor is zero. Therefore, the equation is as follows:

$$
T_{1}+B_{1} n_{2}+B_{0}=2 N u^{2}-D n_{2}
$$

In the equation, $B_{1} n_{2}$ is the dynamic friction torque of mechanical systems, $B_{0}$ is the static friction torque, $T_{1}$ is external torque, $\mu$ is the speed of wind, $n_{2}$ is the revs of wind speed sensor.

\section{The Realization Principle of Passive and Wireless Wind Speed Sensor}

According to the knowledge of Electrical Machinery, We can get the driving torque while the prime motor drags the DC permanent magnet brushless motor as:

$$
T_{1}=C_{M} \Phi \frac{K_{e} n_{1}-2 \Lambda U-U}{r_{a}}+T_{0}
$$


where $T_{0}$ as load torque, $C_{M}$ as DC motor torque constant, $\Phi$ as flux per pole as constant, $n_{1}$ as the motor speed (r/min), $K_{e}$ as electromotive force coefficient $(\mathrm{V} / \mathrm{r} / \mathrm{min}), U$ as the output voltage of the generator, $r_{a}$ as the winding armature circuit resistance, while the pressure drop of two groups of brush and commutator contact resistance is $2 \Delta U$.

We believe that the anemometer achieves balance in such a short time that it has been always at themoment equilibrium state, so we can infer the equation as:

$$
T_{1}+B_{1} n_{2}+B_{0}=2 N u^{2}-D n_{2}
$$

Then the speed can be calculated by the following equation:

$$
C_{M} \Phi \frac{K_{e} n_{1}-2 \Lambda U-U}{r_{a}}+T_{0}+B_{1} n_{2}+B_{0}=2 N u^{2}-D u n_{2}
$$

Because the three cup anemometer using magnetic levitation technology, therefore, $B_{1} n$ and $B_{0}$ are so small that can even be neglected. Otherwise, from the actual structure we can knowledge that $n_{1}=n_{2}=n$, thus we can infer the equation as :

$$
C_{M} \Phi \frac{K_{e} n-2 \Delta U-U}{r_{a}}+T_{0}=2 N u^{2}-D u n
$$

\section{Device Design and Production}

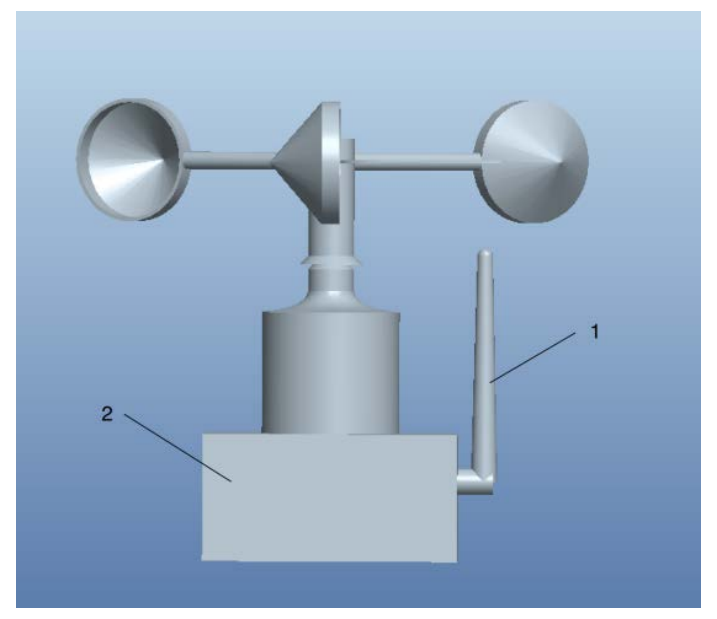

Figure 1

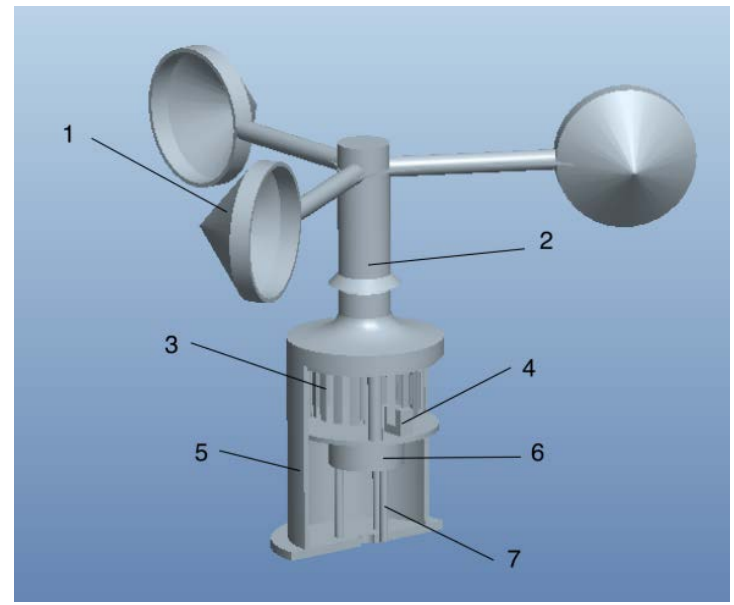

Figure 2

The device is designed to achieve passive characteristics by capturing the wind in the environment and to implementation wireless features by zigbee technology. Therefore, the system consists of three 
parts: the energizing portion, the energizing portion and the communication portion. Measuring section includes improved three-cup wind speed sensor and device stand. Energizing section includes a DC motor, stable voltage boards, extra circuit board, relay and lithium batteries. Communication section includes zigbee communication module. Connection relationship between the mechanical structure is shown in Figure 1 and Figure 2.

In Figure 1,1 is a detachable antenna and 2 is communication control section. In Figure 2, 1 is three-cup wind speed sensor, 2 is shaft, 3 is light board, 4 is photoelectric measurement section ,5 is shell, 6 is DC motor and 7 is pillars.

Each electrical connector module is shown in Figure 3.

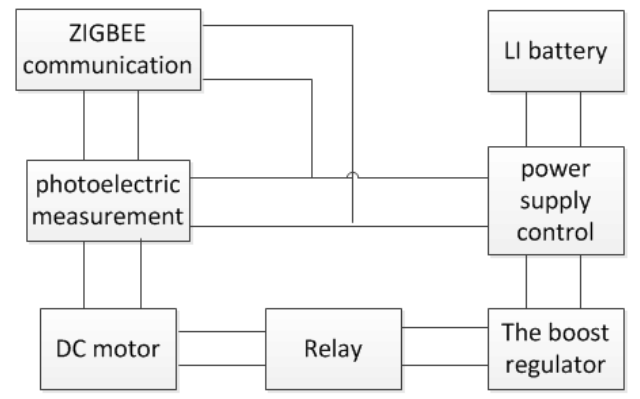

Figure 3

\section{Device Performance Test}

To test the device performance, this paper lets the device and traditional three-cup wind speed sensor which is calibrated under the same experimental environment and test them. The experiment tested the change about the measured number of the two wind speed sensor under the different wind speed. The chart of the testing result is as follows:

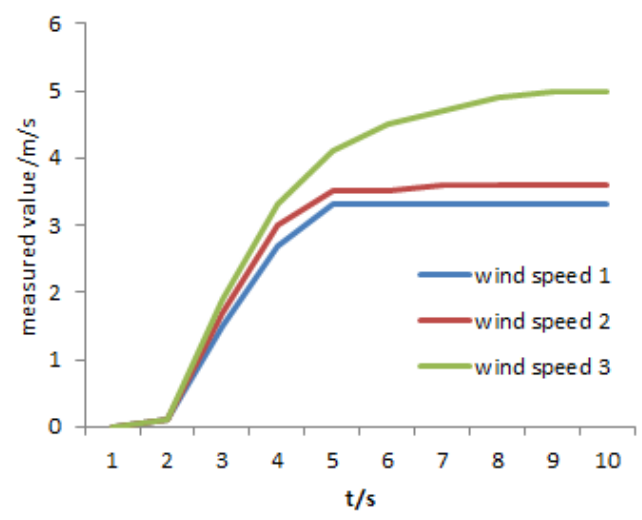

Figure 4 traditional wind velocity meter

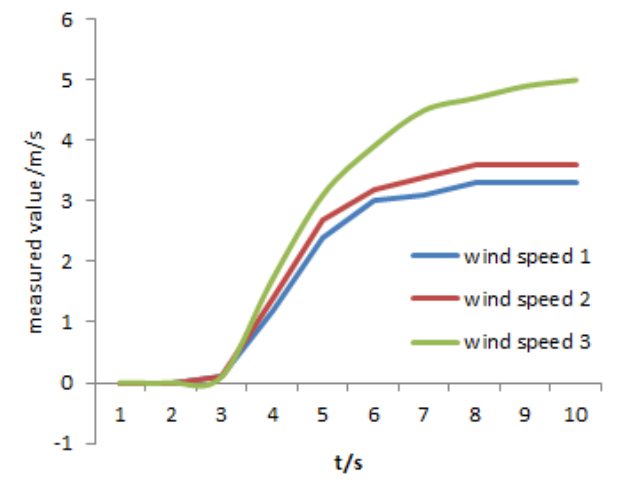

Figure 5 wireless and passive wind velocity meter 
Table 1 the contrast of the results

\begin{tabular}{|c|c|c|c|c|c|c|}
\hline & \multicolumn{3}{|c|}{ steady state value (m/s) } & \multicolumn{3}{c|}{ accommodation time (s) } \\
\cline { 2 - 7 } anemometer & $\begin{array}{c}\text { Wind } \\
\text { speed 1 }\end{array}$ & $\begin{array}{c}\text { Wind } \\
\text { speed 2 }\end{array}$ & $\begin{array}{c}\text { Wind } \\
\text { speed 3 }\end{array}$ & $\begin{array}{c}\text { Wind } \\
\text { speed 1 }\end{array}$ & $\begin{array}{c}\text { Wind } \\
\text { speed 2 }\end{array}$ & $\begin{array}{c}\text { Wind } \\
\text { speed 3 }\end{array}$ \\
\hline $\begin{array}{c}\text { The traditional three cup } \\
\text { anemometer }\end{array}$ & 5 & 3.6 & 3.3 & 9 & 7 & 5 \\
\hline $\begin{array}{c}\text { Wireless passive } \\
\text { anemometer }\end{array}$ & 4.9 & 3.4 & 3.1 & 10 & 8 & 7 \\
\hline
\end{tabular}

\section{Summary}

This paper can get the conclusion from the experimental data: the gap about the wireless and passive wind speed sensor and traditional wind speed sensor on the static performance is small. While on the dynamic performance of gap size and wind speed has a strong relationship, the greater is the wind speed, the smaller is the gap. However, that is all reasonable. Considering the wireless a passive characteristics, this paper concludes that the anemometer has a strong practicability.

\section{References}

[1] Zhou Zhihua. Characteristics Analysis and Experimental Research on the Three-Cup Anemometer[D]. In: Harbin Institute of Technology. 2007:9 24.

[2] Ding Xiang. Design and Study of Permanent Magnet Brushless DC Motor Direct Torque Control System [D]. In: Hunan University. 2009:9 24

[3] Shi Defan. EC9-1 High Dynamic Performance Anemometer and its Design and Test Data[J]. Meteorological hydrological Marine instruments. 1995,(03):12 14.

[4] Wang Jinzhao. The static characteristics of the rotary wind sensor [J]. Acta Meteorologica Sinica. 1984,(06):39 41. 